\title{
Takotsubo cardiomyopathy in an old man with multiple cardiovascular risk factors and chronic anxiety
}

\author{
Savarino Victória Pereira ${ }^{*}$, Ana Feijão ${ }^{1}$, Luís Brás do Rosário ${ }^{2}$ and Humberto Morais ${ }^{3}$ \\ ${ }^{1}$ Serviço de Cardiologia, Hospital Américo Boavida, Luanda, Angola \\ ${ }^{2}$ UTIC, Serviço de Cardiologia, Hospital Santa Maria, Lisboa, Portugal \\ ${ }^{3}$ Departamento de Cardiologia, Hospital Militar Principal/Instituto Superior, Angola
}

\begin{abstract}
We describe a 75-year-old male, with several risk factors for coronary artery disease admitted for ST-segment elevation acute myocardial infarction. Unexpectedly, coronary angiography showed normal coronary arteries; left ventriculography revealed hypercontractility of the basal segments, ballooning of the medial and apical segments of the antero-lateral wall with ejection fraction of $40 \%$, suggesting Takotsubo syndrome. Two-dimensional transthoracic echocardiography on admission confirmed the alterations of the segmental wall motion abnormality observed in left ventriculography. Repeated transthoracic echocardiogram revealed normalized left ventricular systolic function (ejection fraction of $62 \%$ ) without any segmental wall motion abnormality. He was discharged at home with routine appointment. He remainders asymptomatic in sixth month follow up.
\end{abstract}

\section{Introduction}

Acute coronary syndromes (ACS) are frequently encountered in emergency departments (ED) and sometimes differential diagnosis might be challenging [1]. We describe an uncommon case of an elderly male patient with multiple risk factors for coronary artery disease and chronic anxiety who was hospitalized with a diagnosis of STsegment elevation acute myocardial infarction (STEMI). The patient was diagnosed as Takotsubo cardiomyopathy (TC) after coronary angiography and follow up echocardiography.

\section{Case report}

A 75-year-old white male, widowed, with past medical history of hypertension, dyslipidemia, and heavy smoking habits, was admitted to the ED due to an oppressive back pain radiating to precordium and hipersudorese. The patient denied other symptoms, such as palpitations, nausea, vomiting and syncope. He referred, however, great emotional lability and frequents crisis of anxiety since the wife's death three years ago.

The electrocardiogram showed ST-segment elevation in leads V2-V5 (Figure 1). In addition, showed also a sinus rhythm, heart rate of 67 beats/ min and first-degree atrioventricular block. The troponin $\mathrm{T}$ was elevated with $425 \mathrm{ng} / \mathrm{L}$. The initial diagnosis was anterior acute ST-segment elevation myocardial infarction (STEMI). He was treated with aspirin and ticagrelor and was immediately referred to cardiac catheterization unit for primary angioplasty. Coronary angiography excluded coronary artery disease (Figures $2 \mathrm{~A}$ and $2 \mathrm{~B}$ ); left ventriculography revealed hypercontractility of the basal segments, balloonization of the apical segments with an ejection fraction (EF) of 40\% (Figures 2C and 2D). Findings are characteristic of Takotsubo cardiomyopathy. The patient was transferred to the intensive coronary unit (ICU). At admission, he was asymptomatic, with an arterial pressure of $104 / 70 \mathrm{mmHg}$ and pulse of 57 beats $/ \mathrm{min}$. The remaining physical examination was unremarkable. Two-dimensional transthoracic echocardiography

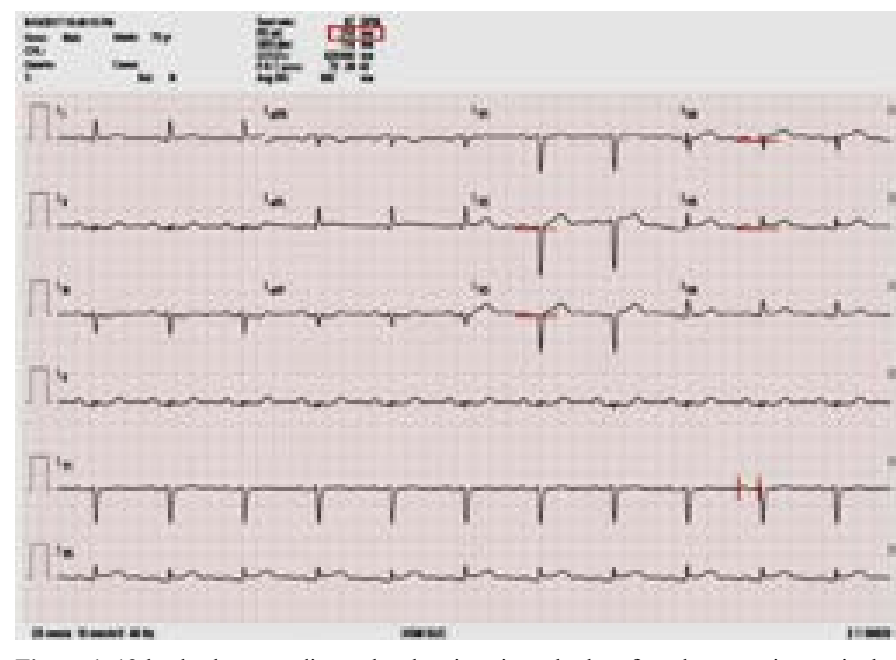

Figure 1. 12 leads electrocardiography showing sinus rhythm, first-degree atrioventricular block and ST-segment elevation in leads V2-V5

(TTE) revealed segmental wall motion abnormality with akinesis and balloonization of all apical segments and basal segmental hiperkinesis, the EF was $44 \%$ (Figure 3). The patient was treated with enalapril, bisoprolol, atorvastatin, bromazepam, and remained asymptomatic, without recurrence of chest pain; no disrhythmias or manifestations

${ }^{\star}$ Correspondence to: Humberto Morais - Hospital Militar Principal/Instituto Superior Rua Pedro Miranda 40-42 Maianga Luanda República de Angola, E-mail: hmorais1@gmail.com

Key words: coronary angiography, transthoracic echocardiogram, Takotsubo syndrome

Received: December 30, 2018; Accepted: January 09, 2019; Published: January 11,2019 
of heart failure were observed. Repeated TTE performed on 4th day, revealed normalized left ventricular systolic function (EF of 62\%) without any wall motion abnormality (Figure 4). He was discharged at home with routine appointment, remaining asymptomatic in sixth month follow up.

\section{Discussion}

Takotsubo cardiomyopathy was first described in Japan, in 1990. It is an acute cardiac syndrome mimicking acute myocardial infarction, and is characterized by chest symptoms, electrocardiographic changes

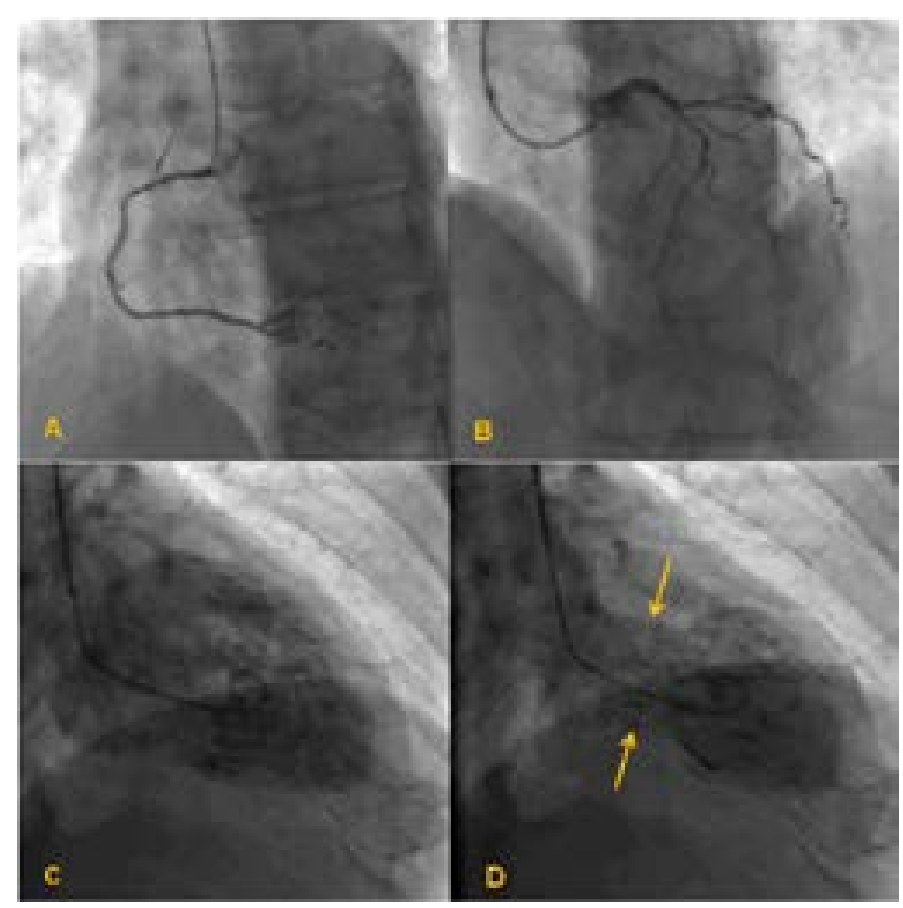

Figure 2. Coronarioventriculography. Coronary angiography showing normal right (A) and left (B) coronary arteries, Left ventriculography showing peculiar ballooning in systole with hiperkinesis of basal segments (yellow arrow) (B)

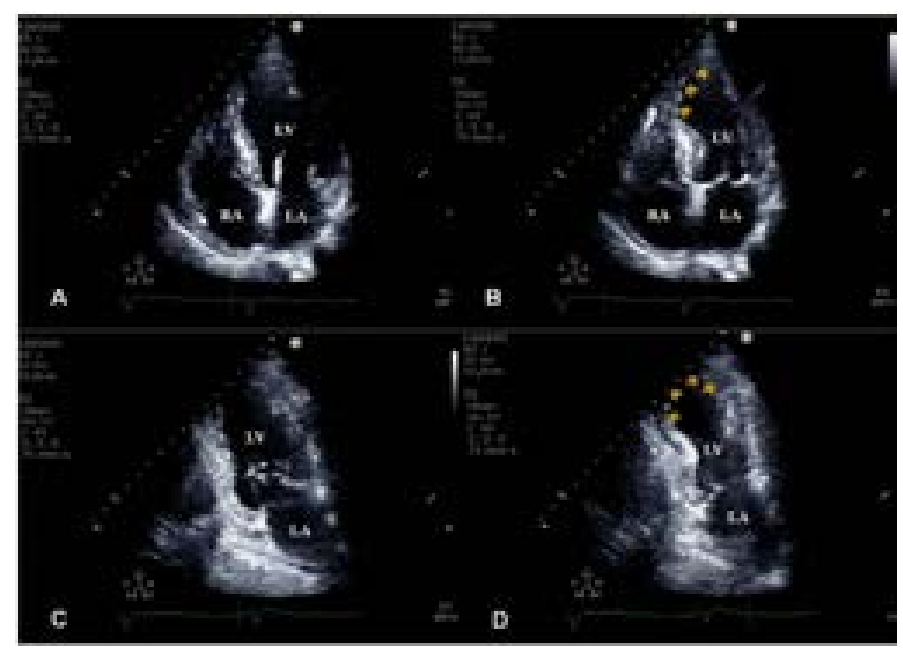

Figure 3. Transthoracic echocardiography Apical four-chamber view A - diastole B systole showing hypokinesis of mesoseptal segments and balloonization apical segments (yellow arrowhead) with hyperkinesis of the basal segments. Apical two-chamber view C diastole $\mathrm{D}$ - systole showing hypokinesis of mesosanterior segments and akinesis of apical segments (yellow arrowhead) with hyperkinesis of the basal segments. LA - Left atrium. RA - Right atrium, LV - Left ventricle

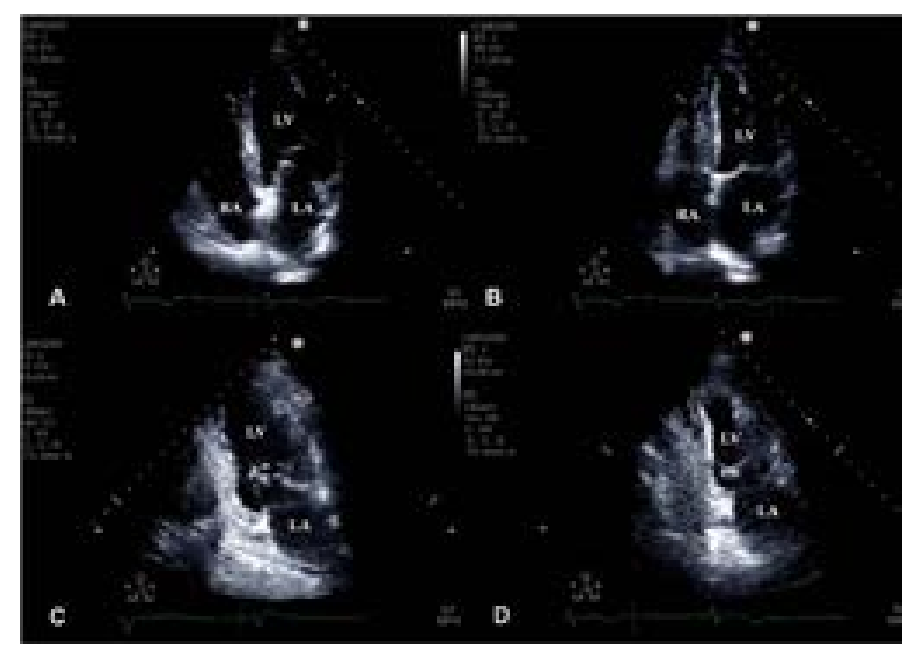

Figure 4. Transthoracic echocardiography (four days after admission) showing normalizations of left ventricular contractility. Apical four-chamber in diastole (A) and in systole (B). Apical two-chamber view in diastole (C) and in systole D. LA - Left atrium. RA - Right atrium, LV - Left ventricle

and reversible regional wall motion abnormality in the apical to mid segments of the left ventricle in the absence of significant atherosclerotic narrowing of epicardial coronary artery [2]. It is often precipitated by a stressful event: physical or emotional event [2-4]. TC predominantly affects postmenopausal women, accounting for about $90 \%$ of the cases observed, with a mean age between 62 and 76 years [2-4], which contrasts with the case described herein - an old man with multiple risk factors for coronary disease -, making it an uncommon case. Furthermore, other aspect that makes this case uncommon is the precipitation factor. In men, physical stress rather than emotional stress is much more associated with the TC $[2,5]$. We believe that chronic anxiety resulting from the wife's death three years ago, with frequent crisis of acute anxiety was the trigger factor in our patient. John Madias point out that history of anxiety and/or depression in patient with TC needs further exploration [6].

The clinical presentation of TC is often indistinguishable from that of an acute coronary syndrome [2-4]. $1,7 \%$ to $2,2 \%$ of patients with suspected ACS have TC [4,7]. Moreover, there is a gender-specific prevalence that is higher in women, ranging from $6 \%$ to $9,8 \%$, whereas the prevalence of TC among male patient with an ACS is below 0,5\% [8]. Our patient is a man with chest pain and ST-segment elevation on the ECG and elevation of troponin T, making the diagnosis of STEMI highly probable until proven otherwise.

In a retrospective study involving $33 \mathrm{TC}$ patients, the authors proposed criteria with high specificity and sensitivity to distinguish TC from anterior myocardial infarction (AMI). These criteria consist of the combined absence of Q waves, reciprocal ST segment changes, ST elevation in V 1 lead and presence of ST elevation in derivation Avr [9]. In addition to these electrocardiographic criteria, the early use of ETT also seems to be useful in the differential diagnosis of acute coronary syndrome and Takotsubo cardiomyopathy [10], and should be part of the workflow when approaching the patient with chest pain in the ED. TTE can provide useful information about LV morphology and regional and global systolic or diastolic function. In addition, the severity, specific findings that have been associated with TC, such as LV outflow tract obstruction, mitral regurgitation and right ventricular involvement, can also be detected [11]. Coronary angiography remains however, mandatory to differentiate TC for AMI. 
Our patient was directly referred to cardiac catheterization unit from ED for primary angioplasty. Coronary angiography excluded coronary artery disease, ventriculography revealed hypercontractility in the basal segments, balloonization of the apical segments with an EF of 40\%, confirming diagnosis of Takotsubo cardiomyopathy, according to Mayo Clinic criteria (2008) [12].

Because the differential diagnosis between TC and AMI usually cannot be established prior coronary angiography, in emergency setting standard treatment of ACS should be implemented. Given initial diagnosis -acute anterior STEMI- our patient was treated in emergency department with aspirin and ticagrelor and was referred to cardiac catheterization unit. After exclusion of coronary artery disease, and in presence of TC, he was treated with beta-blockers and angiotensin-converting enzyme inhibitors until normalization of EF. The statin was maintained for dyslipidemia. The present patient was completely recovered within four day. Complete recovery before 5 days are rare, with very few cases reported in the literature $[7,13,14]$. Aubert, et al. described six cases of transient cardiomyopathy primarily presenting as midventricular ballooning. Most of these cases, as in the patient presented herein, were associated with anxious situation, mild ventricular dysfunction (EF about 40\%) and 1 day to a week for recovery [14]. Findings suggest that duration of recovery may be associated with smaller area of myocardial involvement and less intense illness.

The prognosis of TC is typically favorable. The in-hospital death rate rages from $0 \%$ to within $10 \%$ [4]. However, approximately onethird of patients with TC experience life-threatening complications during the acute phase [11]. The annual recurrence of TC is approximately $1.5 \%,[15]$. The patient was discharged at home with routine appointment, remaining asymptomatic in sixth month follow up.

\section{Conclusion}

With the present report, we would also like to emphasize that the early use of echocardiography may be important in the differential diagnosis of chest pain associated with electrocardiogram changes in emergency department. In addition, in order to reduce the unnecessary hospitalization time in the ICU, patients with diagnosis of TC should perform echocardiography daily to evidence recovery of left ventricular systolic function as soon as possible.

\section{Conflict of interests}

None to declare.

\section{Acknowledgments}

None to declare.

\section{Financial support}

None.

\section{References}

1. Bitigen A, Cevik C, Biteker M, Can M, Ozdemir N (2009) Takotsubo cardiomyopathy in a 52 year old patient. Int $J$ Cardiol 132: e23-5. [Crossref]

2. Kurisu S, Kihara Y (2014) Clinical management of takotsubo cardiomyopathy. Circ J 78: 1559-1566. [Crossref]

3. Nóbrega S, Brito D (2012) The "broken heart syndrome": state of the art. Rev Port Cardiol 31: 589-596. [Crossref]

4. Ono R, Falcão LM (2016) Takotsubo cardiomyopathy systematic review: Pathophysiologic process, clinical presentation and diagnostic approach to Takotsubo cardiomyopathy. Int J Cardiol 209: 196-205. [Crossref]

5. Kurisu S, Inoue I, Kawagoe T, Ishihara M, Shimatani Y, et al. (2010) Presentation of Tako-tsubo cardiomyopathy in men and women. Clin Cardiol 33: 42-45. [Crossref]

6. Madias JE (2016) History of anxiety and/or depression in patients with Takotsubo syndrome: A need for further exploration. Int J Cardiol 203: 600. [Crossref]

7. Cesário V, Loureiro MJ, Pereira H (2012) Takotsubo cardiomyopathy in a cardiology department. Rev Port Cardiol 31: 603-608. [Crossref]

8. Schneider B, Athanasiadis A, Sechtem U. Gender-related differences in takotsubo cardiomyopathy. Heart Fail Clin. 2013;9:137-46[Crossref]

9. Kosuge M, Ebina T, Hibi K, Morita S, Okuda J, et al. (2010) Simple and accurate electrocardiographic criteria to differentiate takotsubo cardiomyopathy from anterior acute myocardial infarction. J Am Coll Cardiol 55: 2514-2516. [Crossref]

10. Madias JE (2013) Appropriate implementation of echocardiography in Takotsubo syndrome: earlier and more frequently. Echocardiography 30: 1123-1125 [Crossref]

11. Citro R, Piscione F, Parodi G, Salerno-Uriarte J, Bossone E (2013) Role of echocardiography in takotsubo cardiomyopathy. Heart Fail Clin 9: 157-166.

12. Scantlebury DC, Prasad A (2014) Diagnosis of takotsubo cardiomyopathy. Circ J 78 2129-2139. [Crossref]

13. Kumar S, Mostow N, Grimm RA (2008) Quick resolution of takotsubo cardiomyopathy: a brief review. Echocardiography 25: 1117-1120. [Crossref]

14. Aubert JM, Ennezat PV, Tricot O, Darchis J, Bauchart JJ, et al. (2007) Mid-ventricular ballooning heart syndrome. Echocardiography 24: 329-334. [Crossref]

15. Singh K, Carson K, Usmani Z, Sawhney G, Shah R, et al. (2014) Systematic review and meta-analysis of incidence and correlates of recurrence of takotsubo cardiomyopathy. Int J Cardiol 174: 696-701. [Crossref]

Copyright: (C2019 Pereira SV. This is an open-access article distributed under the terms of the Creative Commons Attribution License, which permits unrestricted use, distribution, and reproduction in any medium, provided the original author and source are credited. 